\title{
Retrospectively self-reported age of childhood abuse onset in a United States nationally representative sample
}

\author{
Alison L. Cammack ${ }^{*}$ and Carol J. Hogue
}

\begin{abstract}
Background: Child abuse is common and several studies have linked it to health outcomes throughout the lifecourse. Recent information about timing of abuse reported retrospectively is underrepresented in the literature, despite its importance to informing target populations for primary prevention of child abuse and studying effects of child abuse. This study uses data from Wave IV (2008-2009) of The National Longitudinal Study of Adolescent Health to Adult Health $(N=14,776)$ to describe distributions of retrospectively self-reported age of onset of childhood emotional, physical, and sexual abuse perpetrated by parents/adult caregivers and sexual abuse perpetrated by other individuals. Information on childhood abuse history was collected when participants were between 24 and 32 years old.

Findings: Parental/adult caregiver perpetrated abuse frequently started in early childhood, particularly sexual abuse. Non-parental/adult caregiver sexual abuse motivated by physical force also started early in boys (median age $=7$. 21 years (95\% Cl: 5.92, 9.05)). Earlier onset of some types of abuse was associated with male sex, not being raised by both biological parents, and low childhood household income.

Conclusions: Future studies should further examine timing of childhood abuse onset and include diverse measures of abuse, including those derived from longitudinal studies and validated reports. If these results are replicated, they suggest that abuse, particularly sexual abuse perpetrated by parents/adult caregivers, often starts in early childhood, and preventive interventions should be designed to protect younger children.
\end{abstract}

Keywords: Child abuse, Sexual abuse, Sexual assault, Physical abuse, Child maltreatment, Trauma

\section{Background}

Adults commonly report having been abused as children, and several studies have linked childhood abuse to various mental and physical outcomes from childhood through late life (Shonkoff and Garner 2012). In samples with good generalizability (e.g., those that used population-based sampling), the prevalence of adult self-reported childhood abuse history ranges from $11-37 \%$ for emotional abuse, $11-15 \%$ for physical abuse, and $6-54 \%$ for sexual abuse, with more women than men reporting history of sexual abuse (Finkelhor 1994; Gorey and Leslie 1997; Felitti et al. 1998; Centers for Disease Control and Prevention (CDC) 2010). For some outcomes, the etiologic fraction that is

\footnotetext{
* Correspondence: acammac@emory.edu

Department of Epidemiology, Emory University, Rollins School of Public Health, 1518 Clifton Rd NE, Atlanta, GA 30322, USA
}

attributable to adverse childhood experiences, including abuse, is particularly high. Afifi (Afifi et al. 2008) reported that up to half of suicide attempts are attributable to childhood adversity.

While many instruments assess retrospective selfreported childhood abuse history (Felitti et al. 1998; Bernstein et al. 2003), except for a recently developed measure (Teicher and Parigger 2015), these measures seldom collect detailed information about timing of abuse onset. Further, despite many epidemiologic studies examining the frequency of abuse via retrospective selfreport (Hovdestad et al. 2015), usually only limited data about age of abuse onset are captured through this method. For example, age of first rape is described in the National Violence Against Women Survey (NVAWS), a nationally representative survey of women and men (Tjaden and Thoennes 2000), and information about 
timing of sexual abuse is available from a nationally representative population-based study conducted in 1985 (Finkelhor et al. 1990), but timing of other forms of childhood abuse, such as physical or emotional abuse, are not included in these assessments. More recent data of timing of abuse onset can be obtained through other methods, including reported abuse cases (e.g., Child Protective Service records) (Administration on Children, Youth and Families, Children's Bureau 2012) and studies that incorporate longitudinal study designs (e.g., Longitudinal Studies on Child Abuse and Neglect) (Runyan et al. 1998).

Although retrospective self-report is a method that is convenient to use in large population-based samples, allowing for assessments that yield good generalizability, it is subject to recall error which compromises internal validity. Some studies have found that a substantial percentage of individuals with documented abuse may not recall abuse as adults (Widom and Shepard 1996; Widom and Morris 1997). However, this source of bias must be balanced against the fact that retrospective studies capture individuals who may not be identified in longitudinal studies, which frequently utilize at-risk populations, and/or those not identified as victims in the criminal justice system. Substantiated abuse only captures a small proportion of truly exposed individuals, and identified children may systematically differ from the overall population of individuals exposed to maltreatment (Gilbert et al. 2009). Some studies have also noted racial biases in substantiated abuse (Dettlaff et al. 2011). In some studies that utilize both longitudinal and retrospective measures of abuse, more individuals report abuse retrospectively (Kendall-Tackett and Becker-Blease 2004). Finally, unlike retrospective studies of adults, longitudinal studies may have compromised internal validity because required reporting may affect willingness to disclose abuse (Amaya-Jackson et al. 2000). Thus, in spite of limitations to retrospective selfreport, others argue that measurement of serious abuse using this method has a worthwhile and important place in the literature, and it may yield information about abuse from individuals that are not captured through other methods (Kendall-Tackett and Becker-Blease 2004; Hardt and Rutter 2004).

Information about age of abuse onset is important for determining target populations for prevention and identification-based interventions. Age of abuse onset may also be an important factor in determining effects of maltreatment. Evidence from the developmental literature stresses the presence of exposure windows of increased susceptibility to the effects of harmful environments (Wachs et al. 2014), and timing of abuse has been specifically linked to severity of subsequent psychopathology in adulthood (Kaplow and Widom
2007). Thus, to examine more recent retrospective self-reports and to expand the number of abuse types examined via this method, the goal of this paper was to describe the age of onset of multiple types of retrospectively self-reported abuse in a nationally representative sample.

\section{Methods}

The National Longitudinal Study of Adolescent to Adult Health ("Add Health") (Harris et al. 2009) interviewed adolescents in grades 7 through 12 during 1994-95 in schools located in 80 communities throughout the United States. Sampling methods and stratification ensured that selected schools were representative of US schools with respect to region of country, urbanicity, school size and type, and race/ethnicity. A subset of participants were followed through ages 24-32 in 2008$2009(n=15,701$; response rate $=80.3 \%)$, when they were queried about history of childhood abuse. Inclusion criteria for the present study $(N=14,776)$ were 1$)$ presence of a Wave IV sampling weight; 2) data for any of the childhood abuse questions in Wave IV. Permission to conduct secondary analyses was approved by the Emory University Institutional Review Board.

\section{Measures}

Abuse history was assessed via five questions through a computer-assisted self interview. Three questions assessed parental/adult caregiver sexual, physical, and emotional abuse, and two questions assessed non-parental/adult caregiver sexual abuse motivated by physical force and non-physical threats (Harris et al. 2009; Briere and Elliott 2003; Crowley et al. 2003; Straus et al. 1998). Parental/ adult caregiver abuse was asked by the questions, "Before your 18th birthday, how often did a parent or other adult caregiver say things that really hurt your feelings or made you feel like you were not wanted or loved?", "Before your $18^{\text {th }}$ birthday, how often did a parent or adult caregiver hit you with a fist, kick you or throw you down on the floor, into a wall, or down stairs?", and "Before your $18^{\text {th }}$ birthday, how often did a parent or other adult caregiver touch you in a sexual way, force you to touch him or her in a sexual way, or force you to have sexual relations?" Questions about non-parental/adult caregiver sexual abuse were phrased as, "Have you ever been forced, in a nonphysical way, to have any type of sexual activity against your will? For example, through verbal pressure, threats of harm, or by being given alcohol or drugs? Do not include any experiences with a parent or adult caregiver", and "Have you ever been physically forced to have any type of sexual activity against your will? Do not include any experiences with a parent or adult caregiver". For nonparental/caregiver abuse, we defined abuse as occurring before age 18. Participants were asked how old they were 
in continuous years when each type of abuse started ("How old were you the first or only time this happened?").

Participants were asked to categorize frequency of parental/caregiver abuse $(0,1,2,3-5,6-10$, or more than 10 times), and we dichotomized abuse into present or absent by selecting cut points approximating prevalences in the Adverse Childhood Experiences questionnaire in a multi-state, population based sample (Centers for Disease Control and Prevention (CDC) 2010). For these data, the cutpoints were 1 or more total times for sexual abuse (both parental/adult caregiver and non-parental/ adult caregiver subtypes), 2 or more times for physical abuse, and 3 or more times for emotional abuse.

\section{Statistical analysis}

The distribution of age at abuse onset was examined as a continuous variable, with means and percentiles for individual abuse subtypes, including 95\% confidence intervals (CIs). For the subset of individuals who experienced abuse and who had information available for all potential determinants of abuse timing $(N=2,694,1,321$, and 528 for parent/caregiver emotional, physical, and sexual abuse, respectively, and 770 and 565 for nonparent/caregiver sexual abuse motivated by non-physical threats and physical force, respectively), we used multivariate linear regression to model age of onset of each individual abuse type, examining the independent effects of sex, race, childhood household income in 1994 as measured by parent interview (overall response rate for this question $=74 \%$ of participants with baseline Wave I data), and whether one was raised by both biological parents. All analyses incorporated complex weighting to account for the survey design using SAS callable SUDAAN (SUDAAN 11.0.1. Research Triangle Institute, Raleigh, North Carolina; SAS 9.4, SAS Institute, Cary, North Carolina) following guidelines by Chen and Chantala (Chen and Chantala 2006).

\section{Findings}

Six thousand nine hundred nine ten males and 7857 females (unweighted numbers) participated in the survey. Table 1 shows the descriptive characteristics of the study population. The weighted sample reflected the racial/ethnic distribution of the United States. In the study population, abuse was relatively common, and sexual abuse (all types) was more common in girls than boys.

Table 2 describes the population estimated distribution of age of onset of abuse by sex. The distribution of parental/adult caregiver sexual abuse was shifted towards particularly early ages; medians indicated this type of abuse occurred for most individuals before age 8 , and for more than a quarter of those affected, abuse started before the typical age of entry into elementary school.
By contrast, the median age of onset for non-parental/ adult caregiver sexual abuse experienced by girls indicated that it occurred for most at a later age than paren$\mathrm{tal} /$ caregiver abuse, most commonly during adolescence. In boys, however, the difference between non-parental/ adult caregiver versus parent/adult caregiver perpetrated sexual abuse was less defined, particularly for nonparental abuse motivated by physical force. Median age of onset indicated that physical and emotional abuse typically started before adolescence for both sexes.

In regression models (Table 3), except for parental/ caregiver sexual abuse, abuse occurred significantly and in some cases substantially earlier in boys than girls. Most other statistically significant effect sizes translated to approximately a one year age difference, compared to unexposed individuals. Childhood household income below $\$ 35,000$ per year was associated with significantly earlier onset of non-parental/caregiver sexual abuse motivated by non-physical threats and physical force. Not being raised by both biological parents was associated with significantly earlier emotional and physical abuse. Compared to non-Hispanic whites, Black race was broadly associated with later onset of abuse. A sensitivity analysis utilizing log transformed age of abuse onset yielded similar associations.

\section{Discussion}

This study adds to the literature describing age of various types of childhood abuse onset via retrospective-self report, a measure that has been underutilized in recent studies, in a nationally representative sample. In this sample, sexual abuse perpetrated by parents/adult caregivers began particularly early. The median onset of sexual abuse perpetrated by parents/adult caregivers is notably younger than that found in older surveys from the 1980s (median ages between 10 and 11 years) (Finkelhor 1986), underscoring the vulnerability of children experiencing this form of victimization and the importance of considering the role of the perpetrator. Our finding of boys reporting some types of sexual abuse on average at an earlier age than girls is consistent with data from the NVAWS, which reported that among boys experiencing rape, $48 \%$ experienced it before age 12 , versus $24 \%$ in girls (Tjaden and Thoennes 2000). Also, parent/caregiver sexual abuse occurring earlier than physical abuse is consistent with previous, limited analyses of these data (Dunn et al. 2013). However, trends for sexual abuse occurring particularly early differ from data relying on reported abuse, where most physical and emotional abuse occurred before age 9, but most sexual abuse occurred after age 9 (Children and Youth and Families Children's Bureau. Childhood Maltreatment 2012). Some have reported that longitudinal child or parent reports of all types of abuse tend to 
Table 1 Study population characteristics

\begin{tabular}{|c|c|c|c|c|}
\hline Characteristic & $\mathrm{N}^{\mathrm{a}}$ & $\begin{array}{l}\text { Total population weighted } \\
\text { percent }(95 \% \mathrm{Cl})\end{array}$ & $\begin{array}{l}\text { Male population weighted } \\
\text { percent }(95 \% \mathrm{CI})\end{array}$ & $\begin{array}{l}\text { Female population weighted } \\
\text { percent }(95 \% \mathrm{Cl})\end{array}$ \\
\hline Age at Wave 4 Interview & 14776 & Mean $=28.83(28.60,29.06)$ & Mean $=28.93(28.69,29.17)$ & Mean $=28.73(28.50,28.96)$ \\
\hline Male & 6919 & $50.72(49.50,51.95)$ & & \\
\hline Female & 7857 & $49.28(48.05,50.50)$ & & \\
\hline \multicolumn{5}{|l|}{ Parental/Adult Caregiver Abuse } \\
\hline Emotional Abuse $\mathrm{b}^{\mathrm{b}}$ & 3575 & $25.61(24.42,26.85)$ & $20.48(19.03,22.01)$ & $30.91(29.22,32.65)$ \\
\hline Physical Abuse ${ }^{c}$ & 1771 & $11.96(11.06,12.92)$ & $11.85(10.67,13.14)$ & $12.07(10.95,13.29)$ \\
\hline Sexual Abuse ${ }^{d}$ & 724 & $4.88(4.37,5.45)$ & $2.49(1.97,3.14)$ & $7.34(6.52,8.26)$ \\
\hline \multicolumn{5}{|l|}{ Non-Parental/Adult Caregiver Sexual Abuse } \\
\hline Motivated by Non-Physical Threat ${ }^{\mathrm{e}}$ & 998 & $7.25(6.63,7.94)$ & $2.27(1.81,2.84)$ & $12.40(11.26,13.64)$ \\
\hline Motivated by Physical Force ${ }^{f}$ & 731 & $5.13(4.65,5.65)$ & $1.45(1.11,1.90)$ & $8.92(8.01,9.93)$ \\
\hline \multicolumn{5}{|l|}{ Race/Ethnicity ${ }^{9}$} \\
\hline Hispanic & 2352 & $11.93(8.97,15.71)$ & $11.99(8.93,15.90)$ & $11.88(8.87,15.73)$ \\
\hline Black & 3213 & $16.02(12.31,20.57)$ & $15.66(11.88,20.36)$ & $16.38(12.61,21.00)$ \\
\hline White & 7871 & $65.77(59.86,71.23)$ & $65.78(59.70,71.38)$ & $65.76(59.77,71.29)$ \\
\hline Asian & 937 & $3.37(2.15,5.24)$ & $3.42(2.16,5.38)$ & $3.31(2.07,5.26)$ \\
\hline Native American & 262 & $1.94(1.49,2.53)$ & $2.12(1.58,2.85)$ & $1.76(1.27,2.43)$ \\
\hline Other & 129 & $0.97(0.72,1.30)$ & $1.03(0.67,1.57)$ & $0.90(0.63,1.29)$ \\
\hline \multicolumn{5}{|l|}{ Childhood Household Income (1994) } \\
\hline$<35000$ per year & 4827 & $43.50(39.47,47.61)$ & $43.00(38.64,47.48)$ & $44.02(39.97,48.14)$ \\
\hline$=>35000$ per year & 6373 & $56.50(52.39,60.53)$ & $57.00(52.52,61.36)$ & $55.98(51.86,60.03)$ \\
\hline \multicolumn{5}{|l|}{ Childhood Household Composition ${ }^{9}$} \\
\hline Not Raised by Both Biological Parents & 4493 & $28.74(26.53,31.07)$ & $27.50(25.06,30.09)$ & $30.02(27.44,32.73)$ \\
\hline Raised by Both Biological Parents & 10272 & $71.26(68.93,73.47)$ & $72.50(69.91,74.94)$ & $69.98(67.27,72.56)$ \\
\hline \multicolumn{5}{|l|}{ Marital Status at Wave 4 Interview ${ }^{9}$} \\
\hline Never Married & 7375 & $50.20(47.46,52.93)$ & $55.01(52.08,57.90)$ & $45.24(42.21,48.31)$ \\
\hline Ever Married & 7390 & $49.80(47.07,52.54)$ & $44.99(42.10,47.92)$ & $54.76(51.69,57.79)$ \\
\hline
\end{tabular}

${ }^{a}$ Unweighted Sample Size

$\mathrm{b}_{594}$ subjects with missing data

c312 subjects with missing data

${ }^{d} 152$ subjects with missing data

e 65 subjects with missing data

f 44 subjects with missing data

${ }^{9}$ Subheadings for variables (other than abuse) may not total to 14,776 due to missing data

increase with age (Gilbert et al. 2009), which differs from some, but not all of our findings.

The effect of interventions for the prevention of child abuse remains unclear, so there is a need for accurate information on characteristics of abuse, such as age of onset, to guide the development of impactful interventions. For example, several interventions shown to increase children's knowledge of abuse and protective behaviors are based in the school setting (Macmillan et al. 2009; Walsh et al. 2015), but these findings suggest that abuse, particularly sexual abuse, may begin before elementary school. This suggests that preventive interventions for early childcare providers and parents may be important to reducing sexual abuse. Also, fewer interventions exist for physical and emotional abuse in school settings (Macmillan et al. 2009); these data suggest that school based interventions for prevention of these exposures may reach many children.

An important limitation of our study, as previously mentioned, is that retrospective self-report may be prone to recall error. Research indicates that adults have the ability to recall events from much of their childhood (Tustin and Hayne 2010), but the extent to which details like timing can be accurately recalled is unclear. Very early abuse may be underreported due to limitations in memory, which implies that the true distribution of abuse onset is shifted to earlier ages. However, we note that these data were collected in early adulthood, which 
Table 2 Population Weighted Age Distribution of Childhood Abuse Onset by Sex

\begin{tabular}{|c|c|c|c|c|c|c|c|}
\hline & $N^{a}$ & Mean $(95 \% \mathrm{Cl})$ & $\begin{array}{l}\text { Median } \\
(95 \% \mathrm{Cl})\end{array}$ & $\begin{array}{l}\text { 10th Percentile } \\
(95 \% \mathrm{Cl})\end{array}$ & $\begin{array}{l}\text { 25th Percentile } \\
(95 \% \mathrm{Cl})\end{array}$ & $\begin{array}{l}\text { 75th Percentile } \\
(95 \% \mathrm{Cl})\end{array}$ & $\begin{array}{l}\text { 90th Percentile } \\
(95 \% \mathrm{Cl})\end{array}$ \\
\hline \multicolumn{8}{|l|}{ Boys } \\
\hline \multicolumn{8}{|c|}{ Parent/Adult Caregiver Abuse } \\
\hline Emotional Abuse & 1337 & $9.57(9.30,9.85)$ & $9.25(8.92,9.53)$ & $4.18(3.89,4.45)$ & $5.88(5.49,6.36)$ & $12.04(11.74,12.45)$ & $14.36(13.93,14.69)$ \\
\hline Physical Abuse & 856 & $9.17(8.76,9.59)$ & $8.37(7.62,9.30)$ & $3.77(3.14,4.20)$ & $5.21(4.81,5.74)$ & $11.94(11.54,12.55)$ & $14.32(13.79,14.78)$ \\
\hline Sexual Abuse & 168 & $7.78(6.93,8.63)$ & $6.36(5.50,7.04)$ & $1.48(0.66,3.37)$ & $4.28(3.51,4.93)$ & $10.37(8.16,12.20)$ & $14.57\left(12.13,^{-}{ }^{b}\right)$ \\
\hline \multicolumn{8}{|c|}{ Non- Parental/Adult Caregiver Sexual Abuse } \\
\hline $\begin{array}{l}\text { Motivated by } \\
\text { Non-Physical Threat }\end{array}$ & 148 & $10.66(9.66,11.66)$ & $10.43(7.91,12.41)$ & $4.46(3.95,5.23)$ & $5.81(5.15,7.20)$ & $14.51(13.05,15.35)$ & $15.91\left(14.96,-^{-}\right)$ \\
\hline $\begin{array}{l}\text { Motivated by } \\
\text { Physical Force }\end{array}$ & 102 & $8.48(7.60,9.37)$ & $7.21(5.92,9.05)$ & $2.83(1.46,4.52)$ & $4.97(4.32,5.60)$ & $11.72(9.25,13.30)$ & $14.12(12.38,15.41)$ \\
\hline \multicolumn{8}{|l|}{ Girls } \\
\hline \multicolumn{8}{|c|}{ Parent/Adult Caregiver Abuse } \\
\hline Emotional Abuse & 2238 & $10.07(9.81,10.34)$ & $9.92(9.54,10.75)$ & $4.11(3.85,4.29)$ & $5.96(5.61,6.42)$ & $12.96(12.67,13.29)$ & $14.76(14.57,14.93)$ \\
\hline Physical Abuse & 915 & $9.89(9.55,10.23)$ & $9.46(8.86,9.99)$ & $4.15(3.83,4.38)$ & $5.74(5.22,6.27)$ & $12.99(12.53,13.48)$ & $14.81(14.50,15.08)$ \\
\hline Sexual Abuse & 556 & $8.18(7.80,8.56)$ & $7.51(6.87,8.10)$ & $2.69(2.35,3.16)$ & $4.45(4.12,4.82)$ & $10.59(9.79,11.20)$ & $13.33(12.52,13.95)$ \\
\hline \multicolumn{8}{|c|}{ Non- Parental/Adult Caregiver Sexual Abuse } \\
\hline $\begin{array}{l}\text { Motivated by } \\
\text { Non-Physical Threat }\end{array}$ & 850 & $12.68(12.31,13.06)$ & $13.76(13.32,14.12)$ & $4.89(4.42,5.85)$ & $10.01(8.55,11.15)$ & $15.46(15.22,15.68)$ & $16.40\left(--^{b},-\frac{b}{}\right)$ \\
\hline $\begin{array}{l}\text { Motivated by } \\
\text { Physical Force }\end{array}$ & 629 & $12.52(12.12,12.93)$ & $13.47(12.82,14.08)$ & $5.27(4.62,6.31)$ & $8.85(7.95,10.28)$ & $15.37(15.08,15.62)$ & $16.32\left(--^{b},-\frac{b}{}\right)$ \\
\hline
\end{tabular}

anweighted Sample Size

${ }^{b}$ Value not computed (Denominator of the interpolation is zero)

may have reduced misreporting related to length of time since abuse occurred. Another limitation is that the Add Health study population is representative of students enrolled in grades 7-12 and is not generalizable to children who have dropped out of school, although Add Health did sample continuation schools (alternative schools). Child abuse is linked with school dropout (Porche et al. 2011), so these results may not be representative of all abused children.
This study also has noteworthy strengths, particularly as it relates to diversity. Age of onset of child abuse is an important, poorly understood topic across demographic groups. The study design and methods allowed our findings to be representative of the United States school enrolled population, encompassing all regions of country, urbanicity types, school sizes/types, and racial/ethnic groups.

These data show that child abuse in the United States is common and starts for many children during

Table 3 Linear Regression for Age of Childhood Abuse Onset: Beta Coefficients for Independent Predictors

\begin{tabular}{|c|c|c|c|c|c|c|}
\hline & $\begin{array}{l}\text { Hispanic versus } \\
\text { White (referent) } \\
\text { Beta }(95 \% \mathrm{Cl})\end{array}$ & $\begin{array}{l}\text { Black versus } \\
\text { White (referent) } \\
\text { Beta }(95 \% \mathrm{Cl})\end{array}$ & $\begin{array}{l}\text { Other Race } \\
\text { versus White } \\
\text { (referent) Beta }(95 \% \mathrm{Cl} \text { ) }\end{array}$ & $\begin{array}{l}\text { Childhood Household } \\
\text { Income: }>\$ 35,000 \text { Per } \\
\text { Year versus }<=\$ 35,000 \\
\text { Per Year (referent) } \\
\text { Beta }(95 \% \mathrm{Cl})\end{array}$ & $\begin{array}{l}\text { Not Raised by Both } \\
\text { Biological Parents } \\
\text { versus Raised by Both } \\
\text { Biological Parents } \\
\text { (referent) Beta }(95 \% \mathrm{Cl} \text { ) }\end{array}$ & $\begin{array}{l}\text { Male versus } \\
\text { Female (referent) } \\
\text { Beta }(95 \% \mathrm{Cl})\end{array}$ \\
\hline \multicolumn{7}{|c|}{ Parental/Adult Caregiver Abuse } \\
\hline Emotional Abuse & $1.00(0.36,1.63)^{b}$ & $1.25(0.60,1.90)^{b}$ & $-0.74(-1.71,0.24)$ & $0.20(-0.19,0.60)$ & $-0.94(-1.33,-0.54)^{b}$ & $-0.67(-1.07,-0.27)^{b}$ \\
\hline Physical Abuse & $-0.45(-1.29,0.39)$ & $0.85(0.08,1.61)^{b}$ & $-0.94(-2.07,0.19)$ & $0.06(-0.54,0.65)$ & $-0.80(-1.41,-0.19)^{b}$ & $-0.69(-1.33,-0.06)^{b}$ \\
\hline Sexual Abuse & $-0.62(-1.82,0.59)$ & $0.95(-0.38,2.28)$ & $0.60(-0.83,2.03)$ & $0.52(-0.35,1.39)$ & $0.22(-0.64,1.09)$ & $-0.67(-1.79,0.44)$ \\
\hline \multicolumn{7}{|c|}{ Non- Parental/Adult Caregiver Sexual Abuse } \\
\hline $\begin{array}{l}\text { Motivated by } \\
\text { Non-Physical Threat }\end{array}$ & $-0.87(-2.10,0.36)$ & $0.30(-1.03,1.62)$ & $-0.64(-2.64,1.37)$ & $-0.90(-1.65,-0.14)^{b}$ & $0.13(-0.62,0.88)$ & $-2.37(-3.48,-1.26)^{b}$ \\
\hline $\begin{array}{l}\text { Motivated by } \\
\text { Physical Force }\end{array}$ & $0.62(-0.60,1.85)$ & $0.18(-0.88,1.25)$ & $-1.77(-3.74,0.19)$ & $-1.12(-1.95,-0.29)^{b}$ & $-0.15(-1.13,0.82)$ & $-4.00(-5.06,-2.95)^{b}$ \\
\hline
\end{tabular}

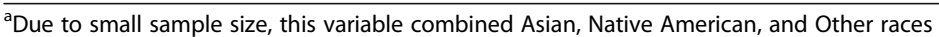


early childhood. Additional studies are needed to confirm our preliminary findings, and researchers should utilize various study designs to examine this topic, while remaining cognizant of the biases each method introduces. Such research is an important precursor to studying the effects of abuse on child and adult outcomes and designing effective preventive measures.

\section{Abbreviations}

Cl: Confidence interval; NVAWS: National violence against women survey

\section{Acknowledgements}

This study was supported by grants T32HD052460 and T03MC07651. This research uses data from Add Health, a program project directed by Kathleen Mullan Harris and designed by J. Richard Udry, Peter S. Bearman, and Kathleen Mullan Harris at the University of North Carolina at Chapel Hill, and funded by grant P01-HD31921 from the Eunice Kennedy Shriver National Institute of Child Health and Human Development, with cooperative funding from 23 other federal agencies and foundations. Special acknowledgment is due Ronald R. Rindfuss and Barbara Entwisle for assistance in the original design. Information on how to obtain the Add Health data files is available on the Add Health website (http://www.cpc.unc.edu/addhealth). No direct support was received from grant P01-HD31921 for this analysis.

\section{Authors' contributions}

ALC conceived the study concept, analyzed the data, and drafted the manuscript. CJH contributed to the study concept, provided feedback for the analysis, and revised the manuscript. Both authors read and approved the final manuscript.

\section{Competing interests}

The authors declare that they have no competing interests, financial and personal relationships with people or organizations that can inappropriately influence this work.

\section{Consent for publication}

Not applicable.

\section{Ethics approval and consent to participate}

This study obtained approval from the Emory University Institutional Review Board (Project number 00039164).

Received: 15 November 2016 Accepted: 8 February 2017 Published online: 13 March 2017

\section{References}

Administration on Children, Youth and Families Children's Bureau. Childhood Maltreatment 2012. Washington D.C.: U.S. Department of Health and Human Services. http://www.acf.hhs.gov/sites/default/files/cb/cm2012.pdf.

Afifi TO, Enns MW, Cox BJ, Asmundson GJ, Stein MB, Sareen J. Population attributable fractions of psychiatric disorders and suicide ideation and attempts associated with adverse childhood experiences. Am J Public Health. 2008;98(5):946-52.

Amaya-Jackson L, Socolar RRS, Hunte WM, Runyan DK, Colindres R. Directly questioning children and adolescents about maltreatment: A review of survey measures used. J Interpers Violence. 2000;15(7):725-59.

Bernstein DP, Stein JA, Newcomb MD, Walker E, Pogge D, Ahluvalia T, et al. Development and validation of a brief screening version of the Childhood Trauma Questionnaire. Child Abuse Negl. 2003;27(2):169-90.

Briere J, Elliott DM. Prevalence and psychological sequelae of self-reported childhood physical and sexual abuse in a general population sample of men and women. Child Abuse Negl. 2003;27(10):1205-22.

Centers for Disease Control and Prevention (CDC). Adverse childhood experiences reported by adults - five states, 2009. MMWR Morb Mortal Wkly Rep. 2010;59(49):1609-13.

Chen PC, Chantala K. Guidelines for Analyzing Add Health Data. 2006, update March 2014; http://www.cpc.unc.edu/projects/addhealth/ documentation/guides/wt_guidelines_20161213.pdf.
Crowley TJ, Mikulich SK, Ehlers KM, Hall SK, Whitmore EA. Discriminative validity and clinical utility of an abuse-neglect interview for adolescents with conduct and substance use problems. Am J Psychiatry. 2003;160(8):1461-9.

Dettlaff A, Rivaux S, Baumann D, Fluke J, Rycraft J, James J. Disentangling substantiation: The influence of race, income, and risk on the substantiation decision in child welfare. Child Youth Serv Rev. 2011;33(9):1630-7.

Dunn EC, McLaughlin KA, Slopen N, Rosand J, Smoller JW. Developmental timing of child maltreatment and symptoms of depression and suicidal ideation in young adulthood: results from the National Longitudinal Study of Adolescent Health. Depress Anxiety. 2013;30(10):955-64.

Felitti VJ, Anda RF, Nordenberg D, Williamson DF, Spitz AM, Edwards V, et al. Relationship of childhood abuse and household dysfunction to many of the leading causes of death in adults. The Adverse Childhood Experiences (ACE) Study. Am J Prev Med. 1998;14(4):245-58.

Finkelhor D. Sourcebook on Child Sexual Abuse. Beverly Hills: Sage; 1986.

Finkelhor D. Current Information on the Scope and Nature of Child Sexual Abuse. Future Child. 1994;4(2):31-53.

Finkelhor D, Hotaling G, Lewis IA, Smith C. Sexual abuse in a national survey of adult men and women: prevalence, characteristics, and risk factors. Child Abuse Negl. 1990;14(1):19-28.

Gilbert R, Widom CS, Browne K, Fergusson D, Webb E, Janson S. Burden and consequences of child maltreatment in high-income countries. Lancet. 2009; 373(9657):68-81.

Gorey KM, Leslie DR. The prevalence of child sexual abuse: integrative review adjustment for potential response and measurement biases. Child Abuse Negl. 1997;21(4):391-8.

Hardt J, Rutter M. Validity of adult retrospective reports of adverse childhood experiences: review of the evidence. J Child Psychol Psychiatry. 2004;45(2):260-73.

Harris KM, Halpern CT, Whitsel E, Hussey J, Tabor J, Entzel P, Udry JR. 2009. The National Longitudinal Study of Adolescent to Adult Health: Research Design. http://www.cpc.unc.edu/projects/addhealth/design.

Hovdestad W, Campeau A, Potter D, Tonmyr L. A systematic review of childhood maltreatment assessments in population-representative surveys since 1990. PLoS ONE. 2015;10(5):e0123366.

Kaplow JB, Widom CS. Age of onset of child maltreatment predicts long-term mental health outcomes. J Abnorm Psychol. 2007;116(1):176-87.

Kendall-Tackett K, Becker-Blease K. The importance of retrospective findings in child maltreatment research. Child Abuse Negl. 2004;28(7):723-7.

Macmillan HL, Wathen CN, Barlow J, Fergusson DM, Leventhal JM, Taussig HN. Interventions to prevent child maltreatment and associated impairment. Lancet. 2009;373(9659):250-66.

Porche MV, Fortuna LR, Lin J, Alegria M. Childhood trauma and psychiatric disorders as correlates of school dropout in a national sample of young adults. Child Dev. 2011;82(3):982-98.

Runyan DK, Curtis PA, Hunter WM, Black MM, Kotch JB, Bangdiwala S. Longscan: A consortium for longitudinal studies of maltreatment and the life course of children. Aggress Violent Behav. 1998;3(3):275-85.

Shonkoff JP, Garner AS. The lifelong effects of early childhood adversity and toxic stress. Pediatrics. 2012;129(1):e232-46.

Straus MA, Hamby SL, Finkelhor D, Moore DW, Runyan D. Identification of child maltreatment with the Parent-Child Conflict Tactics Scales: development and psychometric data for a national sample of American parents. Child Abuse Negl. 1998;22(4):249-70.

Teicher MH, Parigger A. The 'Maltreatment and Abuse Chronology of Exposure' (MACE) scale for the retrospective assessment of abuse and neglect during development. PLoS ONE. 2015;10(2):e0117423.

Tjaden P, Thoennes N. 2000. Full report of the prevalence, incidence, and consequences of violence against women: Findings from the National Violence Against Women Survey. https:/www.ncirs.gov/pdffiles1/nii/183781.pdf. Accessed 1 Sept 2015.

Tustin K, Hayne H. Defining the boundary: age-related changes in childhood amnesia. Dev Psychol. 2010;46(5):1049-61.

Wachs TD, Georgieff M, Cusick S, McEwen BS. Issues in the timing of integrated early interventions: contributions from nutrition, neuroscience, and psychological research. Ann N Y Acad Sci. 2014;1308:89-106.

Walsh K, Zwi K, Woolfenden S, Shlonsky A. School-based education programmes for the prevention of child sexual abuse. Cochrane Database Syst Rev. 2015;4:Cd004380.

Widom CS, Morris S. Accuracy of adult recollections of childhood victimization, Part 2: Childhood sexual abuse. Psychol Assess. 1997;9(1):34-46.

Widom CS, Shepard RL. Accuracy of Adult Recollection of Childhood Victimization: Part 1. Physical Abuse. Psychol Assess. 1996;8(4):412-21. 